\title{
Relación de antecedentes académicos y expectativas iniciales con el bienestar académico de alumnos de primer año de medicina
}

\author{
Alejandra Polanco, Liliana Ortiz, Cristhian Pérez, Paula Parra, Eduardo Fasce, Olga Matus, Graciela Torres, \\ Andrea Meyer
}

Introducción. Los estudiantes de primer año de medicina deben afrontar altas exigencias académicas y personales que influyen en el bienestar y el desempeño académico. Esta investigación analiza la relación de los antecedentes académicos y las expectativas académicas iniciales con el bienestar académico de alumnos de primer año de medicina.

Sujetos y métodos. Estudio cuantitativo, transversal y correlacional. Se aplicaron los cuestionarios UWES-S17, MBI-HSS e involucramiento académico, versión expectativas. Se obtienen los antecedentes académicos y sociodemográficos de una base de datos oficial.

Resultados. Se encontró una relación directa entre las notas de enseñanza media y la dimensión de involucramiento en los estudios del compromiso académico (engagement), una relación inversa con la falta de realización personal del desgaste académico (burnout) y relaciones directas entre las tres dimensiones de las expectativas académicas y el compromiso académico e inversas con la dimensión falta de realización personal del desgaste académico.

Conclusión. Tanto los antecedentes académicos previos como las expectativas académicas iniciales se relacionan con el bienestar académico tras el primer semestre.

Palabras clave. Adaptación universitaria. Bienestar académico. Compromiso académico. Desgaste académico. Expectativas académicas.

Relationship between previous academics background and initial expectations with academic well-being of first year of medical students

Introduction. First year medical students face personal and high academic standards impacting the well-being and academic performance. This research examines the relationship of the academic background and the initial academic expectations with the academic well-being of first year medical students.

Subjects and methods. Quantitative, transversal and correlational study. Applied the questionnaire UWES-S17, MBI-HSS and Academic Involvement, version Expectations. Academic and socio-demographic basis of official data are obtained.

Results. We found direct relationships between the high school grades and dimension of involvement in studies of the academic engagement and inverse with the lack of fulfillment of academic burnout and direct relationships between the three dimensions of the academic expectations and academic engagement and reverse with the lack of personal fulfillment dimension of academic burnout.

Conclusion. Both the previous academic background and initial academic expectations relate to the academic well-being after the first semester.

Key words. Academic burnout. Academic engagement. Academic expectations. Academic well-being. Adaptation university.

\section{Introducción}

El acceso a la universidad supone importantes cambios en la vida del estudiante no sólo en el ámbito académico, sino también en lo social y personal.
La literatura científica señala que la transición de la enseñanza secundaria a la vida universitaria es una etapa particularmente exigente, registrando una mayor incidencia de problemas de adaptación, de rendimiento académico [1] y de permanencia en la
Departamento de Educación Médica. Facultad de Medicina. Universidad de Concepción. Concepción, Chile.

\section{Correspondencia:} Alejandra Polanco Rivera. Departamento de Educación Médica. Facultad de Medicina. Universidad de Concepción. Victor Lamas 1290. Casilla 160-C. CP4030000. Concepción, Chile.

E-mail: polancorivera.ale@gmail.com

Financiación: Proyecto Fondecyt Regular 1121002.

Conflicto de intereses: No declarado.

Competing interests: None declared.

(c) 2014 FEM 
institución educativa a lo largo del primer año de estudios $[2,3]$.

Por otro lado, el estudiante debería asumir un papel principal en el proceso educativo, siendo el responsable de su propio aprendizaje y constructor de su propio conocimiento, de modo que los estudiantes deben estar motivados y comprometidos en su proceso académico para así cumplir sus expectativas.

Algunos estudios $[4,5]$ señalan una relación importante entre bienestar del sujeto y rendimiento académico. Estudiantes con mejor desempeño académico muestran mayor autoeficacia, satisfacción, felicidad y niveles de compromiso y menores niveles de desgaste asociados con el estudio y es común en aquellos que no proyectan abandonar los estudios. Asimismo, el bienestar académico constituye un buen predictor de desempeño académico futuro [6].

Dada la importancia de la salud mental en la calidad de vida de los estudiantes universitarios, se considera relevante estudiar las respuestas cognitivas adaptativas y desadaptativas del estudiante, para lo cual aparecen los conceptos de compromiso y desgaste académico como variables moduladoras del bienestar académico y de la salud del individuo [7].

En relación a las expectativas académicas iniciales, éstas desempeñan un papel relevante en la transición de la enseñanza secundaria a la universitaria, pues influyen en la forma en que los alumnos afrontan las múltiples y complejas tareas de esta transición [8].

Los estudios de la carrera de medicina se caracterizan por una constante y creciente exigencia académica, que demandan del estudiante esfuerzos de adaptación. A ello se agrega la necesidad de una preparación óptima, fundamental para un futuro profesional, en un mercado laboral cada vez más competitivo. Adicionalmente, la carrera se desarrolla en un periodo del ciclo vital con características que le son propias: la adolescencia y la adultez joven. Como resultado, se postula que el estrés que soporta un estudiante de medicina durante su adiestramiento es obligadamente alto, con riesgo de menoscabo de su salud mental $[9,10]$.

Un estudio realizado en una muestra de estudiantes de odontología, enfermería, psicología y de primero a séptimo año de medicina de una universidad chilena, mostró un nivel de prevalencia de estrés académico percibido del 36,3\%, mayor en mujeres que en hombres. Medicina aparece como la carrera con mayores niveles de estrés, los que son acentuadamente más altos en los primeros años respecto de los últimos [11].

En ese proceso de adaptación a la vida universitaria surge el bienestar académico como uno de los indicadores más utilizados y que más claramente se relaciona con la eficacia del afrontamiento al estrés, influyendo así en la aparición de este trastorno psicológico [12].

Actualmente, las instituciones de educación superior procuran elevar la calidad de la docencia a través de investigaciones que permitan analizar las diferentes variables que influyen en el bienestar académico con el objeto de obtener información relevante que permita desarrollar futuras estrategias para favorecer la adaptación, entendida como un proceso que involucra el desempeño académico de los alumnos y el crecimiento personal del estudiante, y así sobrellevar las demandas de la educación superior [11] durante la fase de transición a la vida universitaria.

\section{Sujetos y métodos}

Se realizó un estudio cuantitativo, no experimental, de corte transversal y alcance correlacional. La población estuvo compuesta por estudiantes que durante el año 2012 ingresaron al primer año de pregrado en medicina en tres universidades de la región de Bío-Bío, Chile. A partir de un muestreo no probabilístico por accesibilidad, se obtuvo una muestra de 184 estudiantes. De éstos, un 53,26\% $(n=98)$ eran hombres, y un $45,65 \%(n=84)$, mujeres (dos casos no informaron al respecto). Sus edades se ubicaban entre 18 y 28 años, con una media de 19,17 \pm 1,27 años.

Para evaluar el compromiso académico de los alumnos se utilizó la versión española extendida del cuestionario UtrechWork Engagement Scale Student (UWES-S17), de Schaufeli y Bakker (2003), que presenta 17 afirmaciones con manifestaciones de vigor, absorción y dedicación ante los estudios, para las cuales el estudiante debió responder en base a la frecuencia de ocurrencia en el tiempo utilizando una de siete alternativas en formato Likert (0: ninguna vez; 1 : pocas veces al año; 2 : una vez al mes o menos; 3 : pocas veces al mes; 4 : una vez por semana; 5: pocas veces por semana; 6 : todos los días). $\mathrm{Si}$ bien los autores originales ofrecen una traducción de la UWES-S17 al castellano, se usó la versión revisada y validada en alumnos universitarios chilenos por Parra [13], quien identificó dos factores en el instrumento: involucramiento y satisfacción con los estudios.

La medición del desgaste académico, se realizó a través de la versión adaptada a estudiantes del inventario de burnout de Maslach (MBI-HSS). Esta versión está constituida por 22 ítems con descrip- 
ciones de conductas, pensamientos y afectos ante los cuales el sujeto debía responder según la frecuencia con que los había experimentado. Para esto se debió usar una escala en formato Likert de siete alternativas (0: nunca; 1 : pocas veces al año o menos; 2: una vez al mes o menos; 3: unas pocas veces al mes; 4: una vez a la semana; 5 : pocas veces a la semana; 6: todos los días). De acuerdo con Pérez et al [14], los 22 ítems se agrupaban en tres subescalas, consistentes con el modelo teórico trifactorial de Maslach: agotamiento emocional, despersonalización y falta de realización personal [15].

Para medir las expectativas iniciales de los estudiantes se utilizó el cuestionario de involucramiento académico, versión expectativas, de Almeida y Soares [16], traducido y validado en Chile por Pérez et al (en preparación), que evalúa aquellos aspectos que los estudiantes esperaban encontrar o lograr con su ingreso en la universidad. Este es un instrumento de autocumplimiento de 38 ítems en formato Likert, en los cuales se presentó a los alumnos una afirmación y éstos debían responder según su grado de acuerdo utilizando una de cinco alternativas de respuesta (1: nunca o casi nunca; 2 : rara vez; 3 : a veces; 4 : frecuentemente; 5 : siempre o casi siempre). De esta forma, una mayor puntuación indicaba expectativas de mayor involucramiento de los alumnos en los diferentes aspectos de la vida universitaria. En su versión original en portugués, el instrumento evalúa cinco áreas o subescalas: involucramiento institucional, involucramiento vocacional, involucramiento social, uso de recursos de la institución e involucramiento curricular [16].

Los antecedentes sociodemográficos de los participantes (sexo, edad, tipo de establecimiento de enseñanza media) se obtuvieron de un cuestionario autoinformado que los alumnos debieron responder como parte de la encuesta.

Finalmente, las puntuaciones de la prueba de selección universitaria (PSU) en las versiones de lenguaje (PSUL), matemáticas (PSUM) y ciencias (PSUC) y las notas de enseñanza media o secundaria (NEM) se obtuvieron del registro académico de cada institución participante.

Para acceder a los alumnos se solicitó una autorización a las instituciones participantes y se les visitó en dos ocasiones: en la primera, se realizó el proceso de consentimiento informado y se les aplicó el cuestionario de involucramiento académico, versión expectativas, y el cuestionario sociodemográfico. Seis meses después se volvió a contactar con ellos para aplicarles las escalas de compromiso académico y desgaste académico.
Tabla I. Estadísticos descriptivos de notas de enseñanza media o secundaria y pruebas de selección universitaria de los estudiantes de medicina de primer año.

\begin{tabular}{lccccc}
\hline & $n$ & Media & DE & Mínimo & Máximo \\
\hline NEM & 174 & 6,53 & 0,29 & 5,50 & 6,90 \\
\hline PSUL & 178 & 739,21 & 46,58 & 574 & 834 \\
\hline PSUM & 178 & 713,99 & 46,83 & 580 & 818 \\
\hline PSUC & 115 & 736,17 & 39,91 & 617 & 825 \\
\hline
\end{tabular}

DE: desviación estándar; NEM: notas de enseñanza media o secundaria; PSUL: prueba de selección universitaria de lenguaje; PSUM: prueba de selección universitaria de matemáticas; PSUC: prueba de selección universitaria de ciencias.

Los datos se procesaron y se realizó un análisis descriptivo de los casos evaluando la distribución de la frecuencia de las respuestas y calculando estadísticos de tendencia central y dispersión. Para evaluar la consistencia interna de los cuestionarios se utilizó el coeficiente de fiabilidad $\alpha$ de Cronbach y se evaluó la capacidad discriminativa de los ítems. Para el análisis bivariado se utilizó la prueba ANOVA y la $r$ de Pearson.

\section{Resultados}

En relación al perfil académico de los encuestados según sus antecedentes de ingresos del grupo total $(n=184)$, la mayoría provenía de establecimientos particulares subvencionados $(n=91 ; 49,46 \%), 66 \mathrm{de}$ particulares pagados (35,87\%), 25 municipalizados $(13,59 \%)$ y dos estudiantes no informaron $(1,09 \%)$.

Dado que algunos alumnos ingresaron mediante procesos de selección especial, no se contó con los antecedentes académicos previos de todos los participantes de la muestra. Asimismo, una universidad sólo solicita los datos de NEM, PSUL y PSUM.

El análisis descriptivo de las variables NEM y PSU, identificando su tendencia central y dispersión asociada, se presenta en la tabla I.

En cuanto a las expectativas de los alumnos al inicio de la carrera, a nivel descriptivo, se encontró que la mayor puntuación fue la dimensión de involucramiento académico y el menor referido a la participación estudiantil. Estos resultados, así como los de fiabilidad del instrumento, se presentan en la tabla II.

En relación al bienestar académico, operacionalizado a través del compromiso y desgaste académico, los instrumentos presentaban una adecuada fia- 
Tabla II. Estadísticos descriptivos y fiabilidad del cuestionario de involucramiento académico, versión expectativas $(n=184)$.

\begin{tabular}{lccccc}
\hline & $\alpha$ & Media & DE & Mínimo & Máximo \\
\hline Involucramiento académico & 0,88 & 49,54 & 6,93 & 21 & 60 \\
\hline Apoyo docente & 0,83 & 25,45 & 5,92 & 10 & 40 \\
\hline Implicación social & 0,78 & 24,54 & 3,37 & 14 & 30 \\
\hline Utilización de recursos & 0,72 & 24,34 & 3,50 & 11 & 30 \\
\hline Participación estudiantil & 0,77 & 8,16 & 2,53 & 3 & 15 \\
\hline
\end{tabular}

DE: desviación estándar.

Tabla III. Estadísticos descriptivos y fiabilidad del UWES-S17 $(n=184)$.

\begin{tabular}{lccccc}
\hline & $\alpha$ & Media & DE & Mínimo & Máximo \\
\hline Involucramiento en los estudios & 0,83 & 51,70 & 12,97 & 12 & 108 \\
\hline Satisfacción con los estudios & 0,74 & 27,28 & 4,13 & 10 & 30 \\
\hline
\end{tabular}

DE: desviación estándar.

bilidad. Los estadísticos descriptivos del compromiso académico se presentan en la tabla III, y en ellos se observan altos niveles de compromiso.

Las puntuaciones de las dimensiones del desgaste académico indican bajos niveles de desgaste ( $\mathrm{Ta}$ bla IV).

De los resultados anteriores se desprende que los estudiantes de primer año de medicina tienen buenos niveles de bienestar académico al final del primer semestre lectivo.

Al comparar los niveles de bienestar según el tipo de establecimiento de educación secundaria o media de origen, utilizando la prueba ANOVA de un factor, se encontró que no existían diferencias significativas entre los tres grupos (municipalizado, particular subvencionado y particular pagado) en ninguna de las dimensiones del compromiso y desgaste académico.

$\mathrm{Al}$ evaluar la correlación entre los antecedentes académicos de los estudiantes (NEM y puntuaciones de la PSU) y los niveles de bienestar en el primer año, se encontró que los que presentaban un mayor involucramiento en los estudios eran aquellos que habían ingresado con una mayor NEM $\left(r_{(172)}=0,22 ; p<\right.$ $0,01)$ y una mayor puntuación en la PSUC $\left(r_{(172)}=\right.$ $0,26 ; p<0,01)$. De igual forma se encontró que quie- nes comunicaban una menor falta de realización personal eran aquellos que habían ingresado con una NEM más alta $\left(r_{(115)}=-0,17 ; p<0,05\right)($ Tabla $\mathrm{V})$.

Por último, al evaluar la relación entre las expectativas iniciales y los niveles de bienestar de los estudiantes de primer año -utilizando el UWES-S17 y el MBI-HSS - con el coeficiente de correlación de Pearson en base a un contraste unilateral, se encontraron correlaciones significativas en varios casos, siendo la de mayor tamaño de efecto aquella identificada entre las expectativas de implicación social al inicio de la carrera y la falta de realización personal experimentada tras el primer semestre $\left(r_{(182)}=\right.$ $-0,38 ; p<0,001)$. No obstante, esta relación fue de carácter inverso (Tabla VI).

\section{Discusión}

Los alumnos que ingresan con mejores antecedentes académicos a la carrera de medicina, en este caso las NEM, presentan mayores niveles de compromiso académico y menores de desgaste académico, es decir, mejores niveles de bienestar académico.

No se encontraron diferencias en los niveles de compromiso y desgaste académico en los alumnos provenientes de los distintos establecimientos de enseñanza secundaria.

Existe una relación directa entre las expectativas académicas de ingreso y el bienestar académico experimentado por los alumnos tras el primer semestre. Esto es relevante porque los ajustes académicos, sociales y personales-afectivos desempeñan un papel importante en el éxito universitario, contribuyendo a los logros académicos y, por ende, a un bienestar general del alumno.

Con el desarrollo de los nuevos enfoques de la educación médica y las nuevas metodologías centradas en el aprendizaje autónomo del alumno es necesario brindar a los estudiantes herramientas para que la adaptación al contexto universitario sea lo más exitosa posible. Aunque en este estudio no se encontró evidencia de estrés o problemas con el bienestar académico de los estudiantes, no se puede obviar la baja participación estudiantil declarada en la escala, las expectativas y el agotamiento emocional en la escala de desgaste.

Así, existe escasa información en relación a las variables afectivas que modulan a los estudiantes universitarios, sobre todo a la carrera de medicina, a pesar de que diversos estudios internacionales, como los de Perales et al [9], Dyrbye et al [17], Kjeldstadli et al [1], Benevides y Gonçalves [18], Díaz [10], Santen et al [19], Fontes et al [20] y Gomathi 
et al [21], señalan que en las carreras de medicina desde primer año existe un deterioro afectivo-emocional provocado por problemas de adaptación al nuevo ámbito universitario y planes académicos rigurosos, asociados además a una baja participación en actividades sociales y recreativas. A medida que progresan en la carrera, todos estos fenómenos se transforman en estrés y otros problemas psicológicos y conductuales que deterioran el bienestar del alumno y su calidad como futuro profesional. Este vacío del conocimiento podría explicarse por la reciente incorporación del concepto de bienestar académico, que proviene de la psicología positiva y su búsqueda del bienestar global del estudiante, y porque todavía la mayoría de los investigadores se ocupan de las variables cognitivas que influyen en el desempeño académico.

Los resultados mostraron que la mayoría de los estudiantes de medicina procedían de establecimientos particulares subvencionados y particulares, con lo que se observa aún la brecha de que los sectores más vulnerables de la población estudiantil no tienen acceso a esta carrera [22].

En relación a las NEM y PSU se puede destacar que, para el ingreso a la carrera de medicina, estos indicadores tienen un peso importante, por lo que sus puntuaciones son generalmente altas y homogéneas. Ahora bien, según lo publicado por Pérez et al [23], las NEM son un mejor predictor de características cognitivas y actitudinales, lo cual es importante en el pregrado y en su desempeño académico.

Al describir las expectativas académicas al inicio de la carrera de medicina se pudo observar que, al principio, la mitad del alumnado está más enfocado en el involucramiento académico, es decir, más dedicados a sus estudios y tareas curriculares, invirtiendo el tiempo en eso. Esto concuerda con estudios internacionales como los de Almeida et al $[3,8]$, Cabanach et al [24] y Salgado et al [25], quienes señalan que el ingreso a una carrera universitaria genera altas expectativas y si se considera que esta carrera es medicina, las expectativas personales son mayores, sobre todo por haber pasado los obstáculos previos al ingreso (enseñanza media, PSU), lo que los llevaría a estar más motivados, tener más autoconfianza en sus capacidades y creencias de autoeficacia y así afrontar situaciones con éxito, generando con ello bienestar general.

Tras el primer semestre, los estudiantes estaban altamente involucrados con sus estudios, lo que se enmarca en el componente conductual de estar esforzándose por lo que se está haciendo, en este caso estudiar, lo que en sí caracteriza a la carrera de me-
Tabla IV. Estadísticos descriptivos y fiabilidad del MBI-HSS $(n=184)$.

\begin{tabular}{llllll}
\hline & $\alpha$ & Media & DE & Mínimo & Máximo \\
\hline Agotamiento emocional & 0,81 & 19,42 & 7,85 & 1 & 36 \\
\hline Despersonalización & 0,68 & 8,68 & 6,32 & 0 & 27 \\
\hline Falta de realización personal & 0,76 & 11,18 & 6,57 & 0 & 37 \\
\hline
\end{tabular}

DE: desviación estándar.

Tabla V. Correlación entre los antecedentes académicos de los estudiantes y sus niveles de bienestar $(n=184)$.

\begin{tabular}{lccccc}
\hline & NEM & PSUL & PSUM & PSUC & PUCS \\
\hline Involucramiento en los estudios & $0,22^{\mathrm{b}}$ & 0,01 & 0,03 & $0,26^{\mathrm{b}}$ & 0,04 \\
\hline Satisfacción con los estudios & 0,11 & 0,06 & $-0,06$ & 0,08 & $-0,02$ \\
\hline Agotamiento emocional & 0,06 & $-0,05$ & $-0,10$ & $-0,17$ & $-0,18$ \\
\hline Despersonalización & $-0,04$ & 0,03 & $-0,05$ & 0,11 & $-0,09$ \\
\hline Falta de realización personal & $-0,17^{\mathrm{a}}$ & 0,08 & $-0,01$ & 0,04 & 0,30
\end{tabular}

a $p<0,05 ;{ }^{b} p<0,01$. NEM: notas de enseñanza media o secundaria; PSUL: prueba de selección universitaria de lenguaje; PSUM: prueba de selección universitaria de matemáticas; PSUC: prueba de selección universitaria de ciencias; PUCS: prueba universitaria de ciencias sociales.

dicina desde su inicio, por lo que podríamos decir que se encuentran comprometidos y enfocados académicamente. En relación a su opuesto, el desgaste académico, los alumnos presentaban un bajo grado de agotamiento o cansancio emocional. Sin embargo, Santen et al [19] observaron que el $21 \%$ de los alumnos de primer año de medicina presentaban un grado moderado de desgaste, que aumentó a medida que progresaban los años de carrera, hasta llegar a un nivel máximo en tercer y cuarto año, momento en que este porcentaje se duplicaba. Por tanto, aunque en este estudio el desgaste no constituye un problema, no hay que soslayarlo teniendo en cuenta los estudios en relación con este tema de Carlotto y Gonçalves [26], Benevides y Gonçalves [18] y Fontes et al [20], quienes mencionan que el agotamiento emocional en los estudiantes de medicina surgiría por el número de disciplinas cursadas, la carga académica y horaria y no tener actividades extracurriculares o tiempo libre. Su perpetuación va minando afectivamente al estudiante hasta desarrollar el desgaste y, con ello, deteriorar el bienestar de los alumnos. 
Tabla VI. Correlación entre las expectativas académicas de ingreso de los estudiantes y sus niveles de bienestar $(n=184)$.

\begin{tabular}{lccccc}
\hline & $\begin{array}{c}\text { Involucramiento } \\
\text { académico }\end{array}$ & $\begin{array}{c}\text { Apoyo } \\
\text { docente }\end{array}$ & $\begin{array}{c}\text { Implicación } \\
\text { social }\end{array}$ & $\begin{array}{c}\text { Utilización } \\
\text { de recursos }\end{array}$ & $\begin{array}{c}\text { Participación } \\
\text { estudiantil }\end{array}$ \\
\hline Involucramiento en los estudios & $0,28^{c}$ & $0,27^{c}$ & $0,23^{c}$ & 0,10 & $0,15^{\mathrm{a}}$ \\
\hline Satisfacción con los estudios & $0,29^{c}$ & $0,24^{c}$ & $0,19^{c}$ & 0,10 & 0,09 \\
\hline Agotamiento emocional & 0,05 & $<0,01$ & $-0,05$ & $0,12^{\mathrm{a}}$ & 0,02 \\
\hline Despersonalización & $-0,04$ & $-0,12$ & $-0,19^{\mathrm{b}}$ & $-0,08$ & 0,01 \\
\hline Falta de realización personal & $-0,34^{c}$ & $-0,26^{c}$ & $-0,38^{c}$ & $-0,21^{\mathrm{b}}$ & $-0,19^{\mathrm{b}}$ \\
\hline${ }^{\mathrm{a}} p<0,05^{\mathrm{b}} p<0,01 ;{ }^{c} p<0,001$. & & & & & \\
\hline
\end{tabular}

Al relacionar los antecedentes académicos de ingreso con el bienestar académico, se encontró que aquellos alumnos que se encontraban más involucrados con sus estudios eran los que tenían mejores NEM y PSUC. Ahora bien, enfocándose sólo en la NEM, se observó que aquellos alumnos que tenían mejor NEM presentaban una mayor realización personal. Cómo se aludió empíricamente con anterioridad, Pérez et al [23] indicaron que los NEM son buenos predictores de desempeño académico porque indican cómo eran como alumnos en la enseñanza media en un medio normalizado (establecimiento educacional). Esto está corroborado por diversas investigaciones $[4,5,7]$ en cuanto a que los alumnos que ya presentaban buenos rendimientos académicos pasados, mostraban mayor autoeficacia $\mathrm{y}$, por ende, mayor compromiso con los estudios, mayor satisfacción, mayor realización personal y, por tanto, un mayor bienestar académico.

Al relacionar las expectativas académicas de ingreso con el compromiso y desgaste académico, se encontró que tres dimensiones de las expectativas -involucramiento académico, apoyo docente e implicación social- se relacionaban significativamente con las dos dimensiones del compromiso académico, por lo que se puede indicar que a mayores expectativas de ingreso, mayor compromiso académico tras el primer semestre, lo cual ya se había evidenciado en dos estudios anteriores [5,27], en que esta relación se corresponde con altos niveles de energía, altas expectativas y satisfacción por la actividad que se realiza.

Respecto al desgaste académico, se observó que su componente falta de realización personal presentaba relaciones significativas, pero de carácter inverso, que involucraban las cinco dimensiones de las expectativas, pero con un mayor peso de tres dimensiones nombradas mayormente con anterioridad en la implicación social, lo cual indicaría que a mayores expectativas al inicio, mayor realización personal al final del primer semestre y, por ende, menor desgaste académico. Esto se relacionaría con lo descrito en el párrafo anterior, en el sentido de que habría una relación positiva entre altas expectativas académicas, mayor compromiso y menor desgaste académico, manifestando un buen bienestar académico de los alumnos de medicina en el primer año.

Ahora bien, el hecho de que hubiera una ponderación alta para la implicación social, tanto para el compromiso como para el desgaste, podría señalar la importancia de la interacción entre compañeros en el primer año y cómo esto actúa de forma positiva para favorecer el bienestar académico.

\section{Bibliografía}

1. Kjeldstadli K, Tyssen R, Finset A, Hem E, Gude T, Gronvold NT. Life satisfaction and resilience in medical school -a six-year longitudinal, nationwide and comparative study. BMC Med Educ 2006; 6: 48.

2. Abdullah M, Elias H, Mahyuddin R, Uli J. Adjustment amongst first year students in a Malaysian university. Eur J Soc Sci 2009; 8: 496-505.

3. Almeida LS, Gonçalves A, Salgueira AP, Soares AP, Machado C, Fernandes EM, et al. Expectativas de envolvimento académico à entrada na universidade: estudo com alunos da Universidade do Minho. Psicologia: Teoria, Investigação e Prática 2003; 1: 3-15.

4. Martínez I, Salanova M. Niveles de burnout y engagement en estudiantes universitarios. Relación con el desempeño y desarrollo profesional. Rev Educ 2003; 3: 361-84.

5. Martínez-Martínez IM, Bresó-Esteve E, Llorens-Gumbau S, Grau-Gumbau R. Bienestar psicológico en estudiantes universitarios: facilitadores y obstaculizadores del desempeño académico. Anales de Psicología 2005; 21: 170-80.

6. Garbanzo G. Factores asociados al rendimiento académico 
en estudiantes universitarios, una reflexión desde la calidad de la educación superior pública. Rev Educ 2007; 31: 43-63.

7. Caballero C, Abello R, Palacio J. Relación del burnout y el rendimiento académico con la satisfacción frente a los estudios en estudiantes universitarios. Rev Avances Psicol Latinoam 2007; 25: 98-111.

8. Almeida LS, Fernandes EM, Soares AP, Vasconcelos R, Freitas A. Envolvimento académico: confronto de expectativas e comportamentos em universitários do $1 .^{\circ}$ ano. Psicologia e Educação 2003; 2: 57-70.

9. Perales A, Sogi C, Morales R. Estudio comparativo de salud mental en estudiantes de medicina de dos universidades estatales peruanas. Anales Fac Med Univ Nacional Mayor San Marcos 2003; 64: 239-46.

10. Díaz Y. Estrés académico y afrontamiento en estudiantes de medicina. Rev Hum Med 2010. URL: http://scielo.sld.cu/ scielo.php?script=sci_arttext\&pid=S1727-81202010000100007. [08.07.2012].

11. Cova-Solar F, Alvial W, Aro M, Bonifetti A, Hernández M, Rodríguez C. Problemas de salud mental en estudiantes de la Universidad de Concepción. Terapia Psicológica 2007; 25 : 105-12.

12. Fernández C, Polo M. Afrontamiento, estrés y bienestar psicológico en estudiantes de educación social de nuevo ingreso. EduPsykhé 2011; 10: 177-92.

13. Parra P. Efecto del engagement académico sobre el rendimiento teórico y práctico [tesis de maestría]. Concepción: Universidad de Concepción; 2011.

14. Pérez C, Parra P, Fasce E, Ortiz L, Bastías N. Estructura factorial y confiabilidad del inventario de burnout de Maslach en universitarios chilenos. Revista Argentina de Clínica Psicológica 2012; 21: 255-64.

15. Aguayo R, Vargas C, De la Fuente E, Lozano L. A meta-analytic reliability generalization study of the Maslach Burnout Inventory. Int J Clin Health Psychol 2011; 11: 343-61.

16. Almeida L, Soares A. Transição para a universidade: apresentação e validação do Questionário de Expectativas Acadêmicas (QEA). Actas do VI Congresso Galaico-Português de Psicopedagogia. Centro de Estudos em Educação e Psicologia Universidade de Minho 2001; 2: 899-909.
17. Dyrbye L, Thomas M, Shanafelt T. Medical student distress: causes, consequences, and proposed solutions. Mayo Clin Proc 2005; 80: 1613-22.

18. Benevides A, Gonçalves M. Transtornos emocionais e a formação em medicina: um estudo longitudinal. Rev Bras Educ Med 2009; 33: 10-23.

19. Santen S, Holt D, Kemp J, Hemphill R. Burnout in medical students: examining the prevalence and associated factors. Southern Med J 2010; 10: 758-63.

20. Fontes E, Andrade S, Rodrigues A, Vieira E, Matos T. Burnout syndrome and associated factors among medical students: a cross-sectional study. Clinics 2012; 67: 573-9.

21. Gomathi K, Ahmed S, Sreedharan J. Psychological health of first-year health professional students in a medical university in the United Arab Emirates. Sultan Qaboos Univ Med J 2012; 12: 206-13.

22. Valdés F, Valdés C, Valdés W. Perfil socioeconómico del estudiante de medicina del primer año de la Universidad de Chile. Año 2009. Rev Med Hum 2009; 1: 48-62.

23. Pérez C, Ortiz L, Parra P. Prueba de selección universitaria rendimiento en enseñanza media y sus variables cognitivoactitudinales de alumnos de medicina. Rev Educ Cienc Salud 2011; 8: 120-7.

24. Cabanach R, Valle A, Piñeiro S, González P. Las creencias motivacionales como factor protector del estrés en estudiantes. Eur J Educ Psycol 2010; 3: 75-87.

25. Salgado A, Martins H, Rocha A, Magalhães A. O problembased learning e suas implicações nas expectativas e vivências académicas dos estudantes do $1 .^{\circ}$ ano de cursos de tecnologias da saúde. Actas do VII Simpósio Nacional de Investigação em Psicología 2010. URL: http://www.actassnip2010.com. [28.08.2012].

26. Carlotto S, Gonçalves S. Preditores da síndrome de burnout em estudantes universitários. Pensamiento Psicológico 2008 4: 101-9.

27. Moral-Roig A, Pallisera-Herrero Y, Santaló-Jurado E, Gras-Pérez ME, Villar-Hoz E. Regulación motivacional, satisfacción y rendimiento académico de los estudiantes de psicología. REP:TE. Revista de Enseñanza de la Psicología: Teoría y Experiencia 2008; 4: 49-65. 